\title{
Modified technique for sacrospinous-sacrotuberous ligament complex colpopexy in apical prolapse: preliminary results of a pilot randomized study
}

\author{
Mohamed S. Sweed*, Hassan A. Mostafa, Hazem M. Sammour, Hisham A. Ashour, \\ Mahmoud A. Nadim, Osama I. Ibrahim
}

Department of Obstetrics and Gynecology, Faculty of Medicine, Ain Shams University, Cairo, Egypt

Received: 02 November 2020

Revised: 08 November 2020

Accepted: 11 November 2020

\section{*Correspondence:}

Dr. Mohamed S. Sweed,

E-mail: drmsweed@med.asu.edu.eg

Copyright: () the author(s), publisher and licensee Medip Academy. This is an open-access article distributed under the terms of the Creative Commons Attribution Non-Commercial License, which permits unrestricted non-commercial use, distribution, and reproduction in any medium, provided the original work is properly cited.

\begin{abstract}
Background: Apical prolapse is frequently encountered following vaginal hysterectomy either or as a primary finding in patients with pelvic organ prolapse. This pilot comparative study introduces a modified sacrospinous sacrotuberous ligament fixation with biologic mesh augmentation which necessitates no special kits to be performed.

Methods: This study was conducted at Department of Obstetrics and gynecology, Ain Shams University, Cairo, Egypt, and Department of Women Health of Bethanien Hospital, Iserlöhn, Germany from March 2018 to May 2020. 40 women with either utero-vaginal or vaginal vault prolapse were randomized to either; group (A): 20 women scheduled for modified sacrospinous-sacrotuberous fixation procedure, or group (B): 20 women scheduled for conventional sacrospinous-sacrotuberous fixation procedure.

Results: Improvement of the Pelvic organ prolapse quantification system (POP-Q) stage from the base line preoperative stage was 1 stage higher in the modified SS/ST-F group compared to the conventional SSF group (3 stage improvement from baseline in SS/ST-F group versus 2 stage improvement only in conventional SSF group).

Conclusions: This pilot study provides a modified sacrospinous sacrotuberous ligament colpopexy technique which is easier to be performed and mastered, does not need the use of special devices, provides better improvement of grade of prolapse and less complications compared to the conventional technique.
\end{abstract}

Keywords: Apical prolapse, Sacrospinous-sacrotuberous fixation, POP-Q, Pelvic organ prolapse

\section{INTRODUCTION}

Apical prolapse is a rather frequent encounter either as a primary finding in patients with pelvic organ prolapse or following vaginal hysterectomy. Several operations and different approaches were presented to manage such a problem. One of the most performed procedures is the sacrospinous ligament fixation. ${ }^{1}$ In 1892 , Zweifel was the first to describe a vaginal vault reconstructive surgery anchoring the prolapsed vault to the sacrotuberous ligament. ${ }^{2}$ Amreich and Reichter introduced sacrspinous ligament fixation some 70 years ago. ${ }^{3}$ Since then, the operation was a subject to several modifications aiming to make it more effective, easier to perform and free of complications. $^{4}$

The vaginal approach is by far the most performed approach. It has been described using a variety of instruments including blunt, angular Deschamps ligature carrier, the Miya Hook ligature carrier, and the Shutt suture punch system..$^{5-7}$ The Autosuture Endostitch, originally designed for endoscopic surgery, was introduced by Schlesinger in $1997 .{ }^{8}$ Quiet recently, vaginal mesh kits 
were used but rapidly fell in disuse because of mesh related complications. ${ }^{9}$

This pilot comparative study introduces a modified sacrospinous sacrotuberous ligament fixation with biologic mesh augmentation which requires no special surgical kits to be performed.

\section{METHODS}

This prospective randomized clinical study was conducted at Department of Obstetrics and gynecology, Ain Shams University, Cairo, Egypt, and Department of Women Health of Bethanien Hospital, Iserlöhn, Germany from March 2018 to May 2020. The study protocol was approved by the Institutional review board of both departments. Women with Pelvic organ prolapse quantification system (POP-Q) stage III and IV of either utero-vaginal prolapse and/or vaginal vault prolapse were enrolled in the study. Women weighed less than 40 or more than $60 \mathrm{~kg}$, body mass index (BMI) $<35 \mathrm{~kg} / \mathrm{m}^{2}$, with recurrent utero-vaginal or vaginal vault prolapse, comorbid stress urinary incontinence, or with persistent risk factor increasing intra-abdominal pressure (example; chronic chest conditions) were excluded from the study. Informed written consent was obtained from all women before participating in the study. The study was registered as a randomized controlled clinical trial at www.trials.gov trial registry with the ClinicalTrials.gov identifier (NCT number): NCT03487328.

After enrollment, women fulfilling the inclusion criteria were randomized equally to either modified or conventional sacrospinous sacrotuberous ligament fixation using computer-generated list with block randomization ratio $1: 1$. The randomization allocation cards were kept in sealed opaque envelopes and were consecutively numbered so that the seal was broken just before the operative intervention. All patients received preoperative antibiotic prophylaxis in the form of $1 \mathrm{~g}$ of cefazolin and $500 \mathrm{mg}$ of metronidazole intravenous.

\section{Modified sacrospinous-sacrotuberous fixation procedure}

The rectovaginal space was opened through the posterior vaginal wall followed by combined sharp and blunt dissection to the level of the ischial spines. The descending rectal septum (pillar) was then perforated, opening the pararectal space. With additional blunt dissection, the ischial spine and coccygeus muscle sacrospinous ligament complex were palpated and identified visually as a shiny white structure at the end of the tunnel. In view of the ligament's deep position, the relatively narrow dissection space and the proximity to the rectum the needle was mounted in line with the axis of, rather than perpendicular to, the needle holder making it well positioned to pass through the ligament and avoiding the pudendal neurovascular bundle.
Delayed absorbable sutures (PDS®II, polydioxanone sutures ethicon- number 1- Johnson and Johnson manufacturer) were placed through the ligament. These are pulley sutures intended to bring the vault up against the sacrospinous ligament complex while everting the vaginal cuff and distributing the tension to reduce the risk of tearing through the vagina. Stability of the anchoring sutures was tested by pulling on the suture threads ensuring that a good bite of the ligament was taken. These sutures were held and left untied until any additional reconstructive procedures are completed (exampleanterior or posterior repair).

A biological mesh (Pelvisoft ${ }^{\circledR}$ mesh, Bard manufacturer, UK) was used to reinforce the connective tissue in the rectovaginal space with. The pulley sutures were passed through the mesh before being passed through the vagina $2 \mathrm{cms}$ from the edge to mitigate the risk of tissue tearing. Trans epithelial stitching for closure of the vaginal mucosa was then performed. The pulley sutures were then tightened bringing the vaginal vault in close apposition to the corresponding sacrospinous sacrotuberous ligament complex. If the procedure was performed bilaterally, the pulley suture on the left side was not securely tightened to avoid bridging of the suspended vagina in front of the rectosigmoid and rectum.

\section{Conventional sacrospinous fixation procedure}

The posterior vaginal wall was opened from the perineum to the apex and the rectovaginal space accessed. The rectovaginal space was dissected by combined sharp and blunt dissection to the level of the ischial spines. The descending rectal septum (pillar) was then perforated, opening the pararectal space. With additional dissection, the ischial spine and coccygeus muscle sacrospinous ligament complex were palpated and identified visually as shiny white structure at the end of the tunnel. The Deschamps ligature carrier, loaded with a non-absorbable suture number 1-monofilament ethibond excel suture (Ethicon $\left.{ }^{\circledR}\right)$, was inserted directly into the ligament at a distance more than $1.5 \mathrm{~cm}$ medial to the ischial spine. Suture placement was either made under vision or blindly after palpating the site of insertion from the ischial spine. We avoided placing the suture too close to the ischial spine so as not to entrap the pudendal nerve. The suture was then grasped with a skin hook and while the Deschamps carrier was removed, a second suture was loaded into the Deschamps ligature carrier and passed through the sacrospinous ligament in a similar manner. One end of each of the sutures inserted through the sacrospinous ligament was placed through the muscular layer of the vagina without penetrating the vaginal skin. The opposite ends of the sutures was left free and held on a small clip forceps. Traction on these sutures brought the vaginal vault directly to the ligament, where a square knot was placed to affix it to the sacrospinous ligament using a buried knot and without transfixing the vagina. A posterior colporrhaphy was carried out in the routine fashion, and 
the vaginal mucosa closed. Tightening of the sutures was done after completion of the associated procedure.

We used an endoscopic video-camera (Endocam ${ }^{\circledR}$ Performance camera head, $50 \mathrm{HZ}$ - Richard wolf $\mathrm{GmbH}$, Germany) mounted on a cystoscope for the purpose of documentation.

The primary outcome of this study was the recurrence of uterovaginal or vaginal vault prolapse during the first postoperative year assessed by POP-Q system. The secondary outcomes included Intra and postoperative complications, operating time, blood loss requiring blood transfusion, injury to the surrounding organs, buttock pain, dyspareunia, urinary tract infection, denovo stress urinary incontinence, recurrence of symptoms or complaints and emergence of anterior compartment defect.

Data were analyzed using Statistical package for social sciences (SPSS) version 24.0 (SPSS Inc, Chicago, IL, USA) on intention-to-treat basis. Parametric numerical data are presented as mean \pm standard deviation (SD), whereas non-parametric numerical data are presented as median with interquartile range. Categorical data are presented as number and percentage. 95\% confidence intervals for mean/median were calculated for major outcomes. A two-group comparison for numerical data was done using the student $t$ test for parametric data and using the Mann-Whitney test for non-parametric data. Categorical data were compared using Fisher exact test or its Freeman-Halton extension. Significance level was set at $\mathrm{p} \leq 0.05$.

\section{RESULTS}

66 women with apical prolapse were assessed for eligibility criteria, of which, 40 women were enrolled in the study (Figure 1). No statistically significant differences were found between the two groups regarding the basal demographic characteristics (age, BMI and parity) or regarding the basal clinical characteristics (type of prolapse and pre-operative POP-Q stage) (Table 1). Eighteen cases from the modified SS/ST-F and 19 cases from the conventional SSF group completed the duration of follow up.

No recurrence of pelvic organ prolapse occurred in either groups. Postoperative POP-Q stage was 1-stage lower in the modified SS/ST-F group compared to the conventional SSF group. However, this difference failed to reach statistical significance (Table 2). On the other hand, change in the POP-Q stage differed significantly between the two groups. Improvement of the POP-Q stage from the base line pre-operative stage was 1 stage higher in the modified SS/ST-F group compared to the conventional SSF group (3 stage improvement from baseline in SS/STF group versus 2 stage improvement only in conventional SSF group) (Figure 3).
Table 1: Comparison between study groups regarding basic demographic and clinical characteristics of both groups.

\begin{tabular}{|c|c|c|c|}
\hline Characteristics & $\begin{array}{l}\text { Modified } \\
\text { SS/ST-F } \\
\text { group } \\
(n=20)\end{array}$ & $\begin{array}{l}\text { Conventional } \\
\text { SSF group } \\
(\mathbf{n}=\mathbf{2 0})\end{array}$ & $\begin{array}{l}\mathbf{P} \\
\text { value }\end{array}$ \\
\hline \multicolumn{4}{|l|}{ Age (years) } \\
\hline Range & $44-56.0$ & $45.0-59.0$ & \multirow{2}{*}{0.54} \\
\hline Mean \pm SD & $50.5 \pm 3.5$ & $51.3 \pm 4.6$ & \\
\hline \multicolumn{4}{|l|}{ BMI $\left(\mathrm{kg} / \mathrm{m}^{2}\right)$} \\
\hline Range & $22.3-34.5$ & $23.6-34.0$ & \multirow{2}{*}{0.23} \\
\hline Mean \pm SD & $28.2 \pm 3.7$ & $29.4 \pm 2.9$ & \\
\hline \multicolumn{4}{|l|}{ Parity } \\
\hline Range & $1-5$ & $1-7$ & \multirow{2}{*}{0.21} \\
\hline Median (IQR) & $2.5(2-3)$ & $3(2-5)$ & \\
\hline \multicolumn{4}{|c|}{ Type of prolapse } \\
\hline Uterine & $17(85 \%)$ & $18(90 \%)$ & \multirow{2}{*}{0.99} \\
\hline Vaginal vault & $3(15 \%)$ & $2(10 \%)$ & \\
\hline \multicolumn{4}{|l|}{ POP-Q stage } \\
\hline Range & $3-4$ & $3-4$ & \multirow{2}{*}{0.76} \\
\hline Median (IQR) & $3.5(3-4)$ & $3(3-4)$ & \\
\hline
\end{tabular}

Table 2: Comparison between study groups regarding postoperative pelvic organ prolapse.

\begin{tabular}{|c|c|c|c|}
\hline & $\begin{array}{l}\text { Modified } \\
\text { SS/ST-F } \\
\text { group }\end{array}$ & $\begin{array}{l}\text { Conventional } \\
\text { SSF group }\end{array}$ & $\begin{array}{l}\mathbf{P} \\
\text { value }\end{array}$ \\
\hline $\begin{array}{l}\text { Recurrence of } \\
\text { prolapse }(\%)\end{array}$ & $0(0 \%)$ & $0(0 \%)$ & - \\
\hline \multicolumn{4}{|c|}{ Postoperative POP-Q stage } \\
\hline Median (IQR) & $0(0-1)$ & $1(0-2)$ & 0.06 \\
\hline $95 \% \mathrm{CI}$ & $0-1$ & $0-2$ & \\
\hline $\begin{array}{l}\text { Difference } \\
\text { between two } \\
\text { groups }(95 \% \mathrm{CI})\end{array}$ & $-1(-1-0)$ & & \\
\hline \multicolumn{4}{|c|}{ Improvement in POP-Q stage } \\
\hline Median (IQR) & $3(3-3)$ & $2(2-3)$ & 0.01 \\
\hline $95 \% \mathrm{CI}$ & $2.7-3.3$ & $2.1-2.8$ & \\
\hline $\begin{array}{l}\text { Difference } \\
\text { between the two } \\
\text { groups }(95 \% \mathrm{CI})\end{array}$ & $1(0-1)$ & & \\
\hline
\end{tabular}

Operative time was statistically significantly shorter in the conventional SSF group compared to the modified SS/STF group (18 (15-21) versus $22 \quad(20-25)$ minutes respectively). However, this difference might not be of clinical significance $(\mathrm{p}=0.003)$. No statistically significant differences were found in the incidence of other complications (Table 3). 

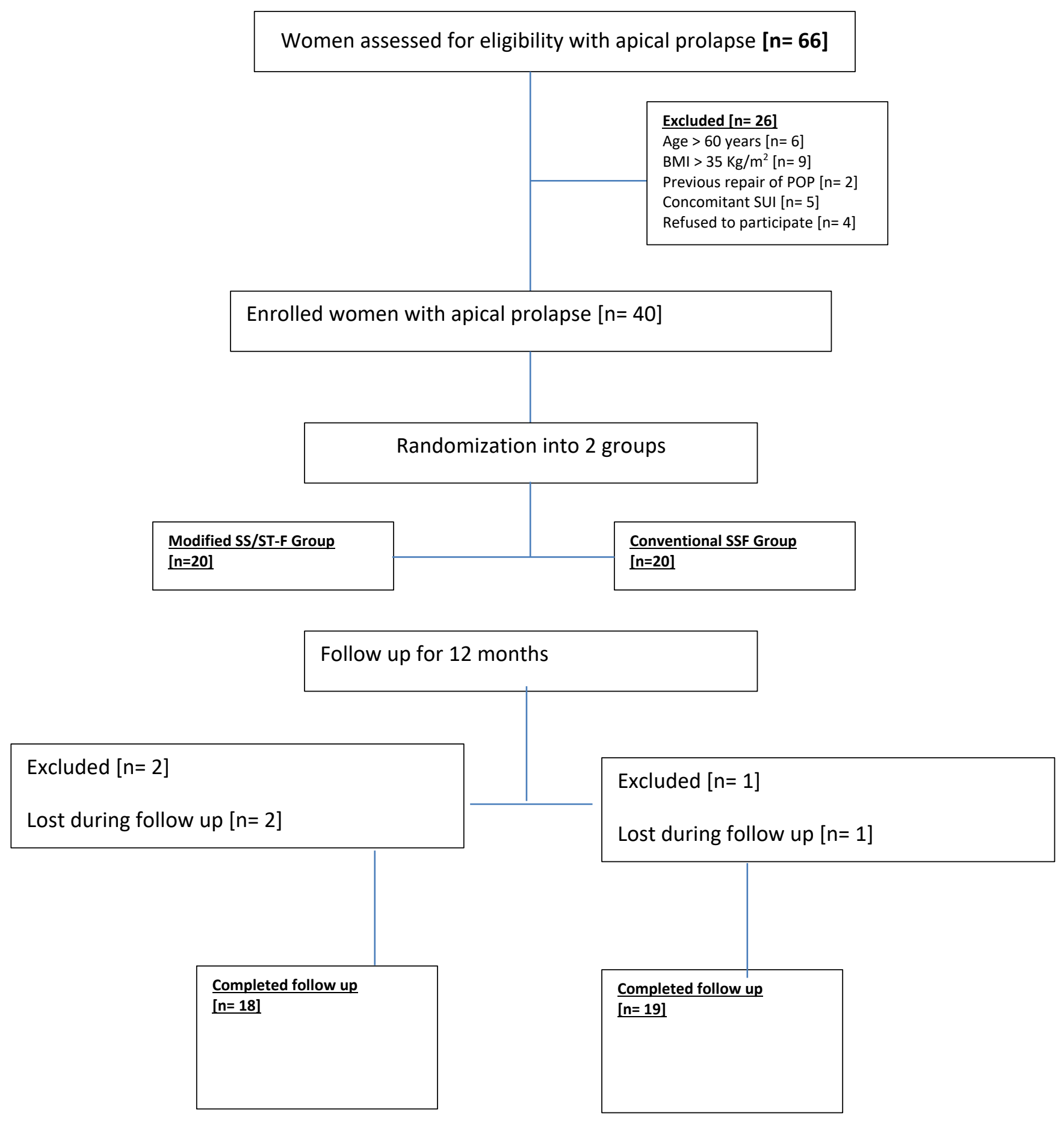

Figure 1. CONSORT 2010 flow diagram showing the recruitment and handling of the study population during the study.

Table 3: Comparison between study groups regarding incidence of surgical complications intra-operatively and during the follow-up period.

\begin{tabular}{|llll|}
\hline Variables & Modified SS/ST-F group & Conventional SSF group & P value \\
\hline Intra-operative complications & & & \\
\hline $\begin{array}{l}\text { Hemorrhage requiring blood } \\
\text { transfusion }\end{array}$ & $1 / 20(5 \%)$ & $1 / 20(5 \%)$ & $>0.05$ \\
\hline Bladder injury & $0(0 \%)$ & $0(0 \%)$ & - \\
\hline Rectal injury & $0(0 \%)$ & $0(0 \%)$ & - \\
\hline
\end{tabular}




\begin{tabular}{|c|c|c|c|}
\hline Variables & Modified SS/ST-F group & Conventional SSF group & $P$ value \\
\hline \multicolumn{4}{|c|}{ Complications during the follow-up period } \\
\hline Urinary tract infection & $2 / 18(11 \%)$ & $3 / 19(16 \%)$ & $>0.05$ \\
\hline De novo stress urinary incontinence & $0(0 \%)$ & $1 / 19(5 \%)$ & $>0.05$ \\
\hline De novo anterior compartment defect & $1 / 18(5.6 \%)$ & $2 / 19(10.5 \%)$ & $>0.05$ \\
\hline Erosion at suture site & $0(0 \%)$ & $2 / 19(10.5 \%)$ & $>0.05$ \\
\hline Gluteal pain & $1 / 18(5.6 \%)$ & $3 / 19(16 \%)$ & $>0.05$ \\
\hline
\end{tabular}

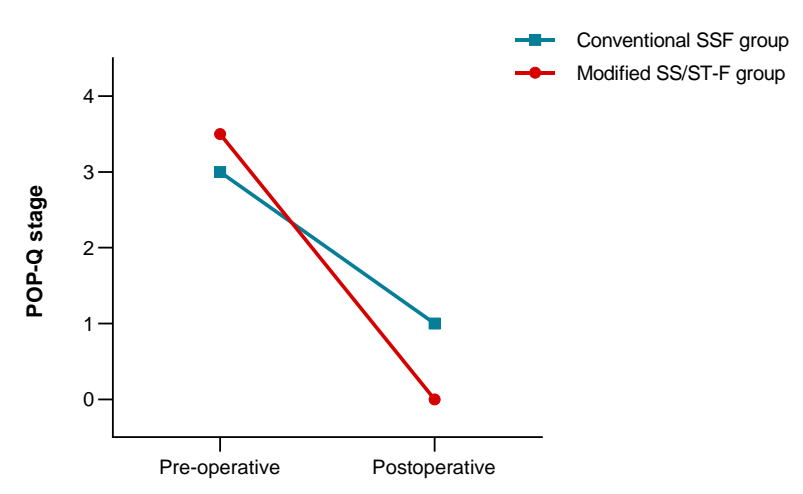

Figure 2: Line graph for the change in the POP-Q stage in the two groups.

\section{DISCUSSION}

In most of the publications, it is recommended in sacrospinous -sacrotuberous fixation to place the sutures at a distance at least $20 \mathrm{~mm}$ medial to the ischial spine and put the suture near to the lower than the upper border of the SSL to avoid injury of the pudendal nerve. ${ }^{10}$ In a cadaveric study, Manning and Arnold concluded that the vascular and nerve anatomy behind and in the vicinity of the sacrospinous ligament is enormously variable and that suture placement two fingerbreadths medial to the spine does not guarantee safety. ${ }^{11}$

In this modified technique, we are essentially making use of the sacrospinous/sacrotuberous complex. This intersection is at the medial one third of the ligament nearer to the sacrum then to the ischial spine. ${ }^{12}$ This is putting the anchoring suture well away from the nerves and ensuring better stability. In the original description of the procedure, the Deschamps ligature carrier was used to pass the suture through the sacrospinous ligament. Since then, several modifications have been proposed and are essentially variations on the way sutures are passed through the sacrospinous ligament. ${ }^{13}$

Morley and DeLancey used a classical needle holder to pass the needle through the ligament and advocated the direct visualization of the sacrospinous ligament and placed three retractors to directly visualize it. ${ }^{14}$ Direct visualization of the ligament has been thought to reduce the rate of complications associated with suture placement. ${ }^{15}$ However, it entails a greater deal of training and surgical expertise. In a cadaveric study, Manning et al compared 6 suture placing instruments in the sacrospinous ligament. They concluded that for vascular safety, the ideal device needs to be compact and that the sharp penetrating component carrying the suture should traverse the shortest distance at the shallowest depth allowing adequate bite. These requirements were by the Caspari, Capio and to a lesser extent by Endostitch. For them, the i-stitch was not safe in thin ligaments. They considered the Deschamp ligature carrier and Miya hook devices a good compromise for the developing world where cost is important. ${ }^{11}$ In this study we used an ordinary long needle holder to pass the suture into the sacrospinous/sacrotuberous complex. The needle is held on the needle holder parallel to its axis so that to allow a perpendicular bite of the sacrospinous/ sacrotuberous complex. For this reason, the needle is not placed perpendicular to the needle holder axis but rather parallel and in line with the axis as if it is a parrot's beak creating a perfect and adequate bite in the ligament and avoiding the needle being pointing to the pudendal neurovascular bundle but rather being parallel to it and hence decreasing the risk of injury.

We used a Polydioxanone monofilament sutures (PDS II) which are made from the polyester poly (p-dioxanone), and are considered the longest-lasting absorbable monofilament wound support commercially available. It takes at least 180 days for a complete absorption of this suture material by hydrolysis. The experimentations made on rabbits and sheep suggest that PDS can be used to fasten ligament sutures and to reinforce ligament grafts. Under extremely favorable soft tissue conditions, the substance can even be used as ligament substitute in knee and other joint surgeries where strength and stability are requested. ${ }^{16}$ We used monofilament ethibond excel suture (Ethicon®) which is non-absorbable sutures in the conventional SSF group. We had two cases of sutures erosions developing at 6 and 9 months of follow up with an associated complaint of troublesome vaginal discharge and dyspareunia. These cases went through an examination under anesthesia and the excess granulation tissue-suture amalgamate was excised. No relapse of the annoying discharge was noted and dyspareunia improved for those cases at 3 and 5 months following the secondary intervention. Based on several publications where non-absorbable sutures were used in SSF and other restorative vaginal procedures. ${ }^{17,18}$ We do not recommend the use of such material for restorative vaginal surgery. In older women the sacrospinous ligament is sometimes thin. ${ }^{11}$ Therefore, testing the stability of the suspending suture is a crucial step to avoid tearing of the ligament. 
Estelle Declas and co-workers published an article detailing their technique of sacrospinous fixation. ${ }^{19}$ This may be the only detailed description of the procedure. However, lots of differences exist when their technique is compared to the one we are proposing. They used nonabsorbable sutures that are attached to vaginal strips buried under the vaginal epithelium, although, they are denuding these bands from epithelium yet there is no guarantee that remnants of epithelium do not form an inclusion dermoid cyst or that the non-absorbable sutures would not cause any complications.

The repair in our technique is augmented by an organic mesh made of collagen. Surgical synthetic mesh is no more recommended for vaginal restorative surgery conducted through the vagina. We could not find too many publications on this issue; however a review of the clinical evidence in this respect is praising the low risks of graft rejection, complications, and infection of organic mesh compared with the synthetic non-absorbable ones. ${ }^{20}$ However, the elevated costs suggest that biological mesh implantation should be evaluated in correlation to the needs of each clinical case. ${ }^{21}$

When bilateral SSF was resorted to, we were not tightly approximating sutures on the left side. We think that this will avoid creation of a kind of bridge that may cause a rectosigmoid dysfunction. When both methods were compared, we found that that the operative time was statistically significantly shorter in the conventional SSF method may be because this was the method the surgeons were used to perform. However, the difference was only about 4 minutes. We did not have any recurrent prolapse cases by the end of a period of follow up that extended for 2 years for the older cases and one year for the lately performed ones. The degree of improvement was statistically significantly better in the modified SS/ST-F group compared to the conventional SSF group.

We had overall 3 cases that developed de novo anterior wall defect. The anterior vaginal wall is the most common site of recurrent prolapse following SSLF. This is probably because the attachment of the vagina to the sacrospinous ligament deviates it posteriorly with a subsequent loss of the anterior wall support. ${ }^{22}$ However; a study by Smilen et al looked at the risk of developing cystocele following SSF. According to them, no statistically significant difference in the rate of recurrent cystocele following SSF with cystocele repair when compared to cystocele repair alone (11.7 versus $9.5 \%, \mathrm{p}>0.05)$. The risk of cystocele after prolapse surgery was increased if anterior colporrhaphy was not done at the time of initial surgery (17.8\% without repair and $9.9 \%$ with repair). ${ }^{23}$ In our study both cases did not have cystocele repair at the time of the initial surgery because it was judged not necessary. The only case that developed de novo stress urinary incontinence belongs to one of these two cases.

The technique we adopted is rendering the operation easy to perform and to be mastered by young surgeons. There is no need for the use of special devices and suture placement is always made under vision. The degree of improvement of the grade of prolapse is much better than in the conventional group with lesser complications. Still, the small sample size could be considered as a limitation to the study, still, the results are considered promising and need further clarification with larger studies.

\section{CONCLUSION}

This pilot study provides a modified sacrospinous sacrotuberous ligament colpopexy technique which is easier to be performed and mastered, does not need the use of special devices, provides better improvement of grade of prolapse and less complications compared to the conventional technique.

\section{ACKNOWLEDGMENTS}

Authors would like to acknowledge Ain Shams University.

Funding: No funding sources

Conflict of interest: None declared

Ethical approval: The study was approved by the Institutional Ethics Committee

\section{REFERENCES}

1. Halaska M. Závěs pochvy prolabující po hysterektomii k lig. sacrospinale--vaginaefixatio sec. Amreich II-Richter [Fixation of the prolapsed vagina to the sacrospinous ligament after hysterectomy--the Amreich II-Richter vaginal fixation operation]. Ceska Gynekol. 1997;62(6):323-9.

2. Rane A, Frazer M, Jain A, Kannan K, Iyer J. The sacrospinous ligament: Conveniently effective or effectivelyconvenient? Journal of Obstetrics and Gynaecology. 2011;31(5):366-70.

3. Richter K. The surgical treatment of the prolapsed vaginal fundus after uterine extirpation. A contribution on Amreich's the sacrotuberal vaginal fixation. Geburtshilfe Frauenheilkd. 1967;27(10):941-54.

4. Aksakal OS, Ozyer SS, Güngör T, Doğanay M, Bilge U, Mollamahmutoğlu L. Comparison of a new technique with Deschamps ligature carrier for sacrospinous ligament fixation. Arch Gynecol Obstet. 2007;276(6):591-4.

5. Veronikis DK, Nichols DH. Ligature carrier specifically designed for transvaginal sacrospinous colpopexy. Obstet Gynecol. 1997;89(3):478-81.

6. Miyazaki FS. Miya Hook ligature carrier for sacrospinous ligament suspension. Obstet Gynecol. 1987;70(2):286-8.

7. Sharp TR. Sacrospinous suspension made easy. Obstet Gynecol. 1993;82(5):873-5.

8. Schlesinger RE. Vaginal sacrospinous ligament fixation with the Autosuture Endostitch device. Am J Obstet Gynecol. 1997;176(6):1358-62.

9. Zhu Q, Shu H, Du G, Dai Z. Impact of transvaginal modified sacrospinous ligament fixation with mesh 
for the treatment of pelvic organ prolapse-before and after studies. Int J Surg. 2018;52:40-3.

10. Cayrac M, Letouzey V, Ouzaid I, Costa P, Delmas V, Tayrac R. Anterior sacrospinous ligament fixation associated with paravaginal repair using the Pinnacle device: an anatomical study. Int Urogynecol J. 2012;23(3):335-40.

11. Manning JA, Arnold P. A review of six sacrospinous suture devices. Aust N Z J Obstet Gynaecol. 2014;54(6):558-63.

12. Lazarou G, Grigorescu BA, Olson TR, Downie SA, Powers K, Mikhail MS. Anatomic variations of the pelvic floor nerves adjacent to the sacrospinous ligament: a female cadaver study. Int Urogynecol J Pelvic Floor Dysfunct. 2008;19(5):649-54.

13. Pollak J, Takacs P, Medina C. Complications of three sacrospinous ligament fixation techniques. Int $\mathrm{J}$ Gynaecol Obstet. 2007;99(1):18-22.

14. Morley GW, DeLancey JO. Sacrospinous ligament fixation for eversion of the vagina. Am J Obstet Gynecol. 1988;158(4):872-81.

15. David-Montefiore E, Garbin O, Hummel M, Nisand I. Sacro-spinous ligament fixation peri-operative complications in 195 cases: visual approach versus digital approach of the sacro-spinous ligament. Eur J Obstet Gynecol Reprod Biol. 2004;116(1):71-8.

16. Diehl K, el-Ahmad M, Franzl K. Capsular ligament surgery of the knee joint with resorbable materials. 5year clinical experience with Vicryl and PDS ligaments. Z Orthop Ihre Grenzgeb. 1987;125(5):46772 .

17. Hamdy MA, Ahmed WAS, Taha OT, Abolill ZM, Elshahat AM, Aboelroose AA. Late suture site complications of sacrospinous ligament fixation. Eur J Obstet Gynecol Reprod Biol. 2019;242:126-30.

18. Yazdany T, Yip S, Bhatia NN, Nguyen JN. Suture complications in a teaching institution among patients undergoing uterosacral ligament suspension with permanent braided suture. Int Urogynecol $\mathrm{J}$. 2010;21(7):813-8.

19. Declas E, Giraudet G, Delplanque S, Rubod C, Cosson M. How we perform a posterior sacrospinous ligament fixation by the vaginal route. Int Urogynecol J. 2020;31(7):1479-81.

20. Culligan PJ, Littman PM, Salamon CG, Priestley JL, Shariati A. Evaluation of a transvaginal mesh delivery system for the correction of pelvic organ prolapse: subjective and objective findings at least 1 year after surgery. Am J Obstet Gynecol. 2010;203(5):506.e1-6.

21. Peppas G, Gkegkes ID, Makris MC, Falagas ME. Biological mesh in hernia repair, abdominal wall defects, and reconstruction and treatment of pelvic organ prolapse: a review of the clinical evidence. Am Surg. 2010;76(11):1290-9.

22. Dietz V, Huisman M, de Jong JM, Heintz PM, van der Vaart CH. Functional outcome after sacrospinous hysteropexy for uterine descensus. Int Urogynecol J Pelvic Floor Dysfunct. 2008;19(6):747-52.

23. Smilen SW, Saini J, Wallach SJ, Porges RF. The risk of cystocele after sacrospinous ligament fixation. Am J Obstet Gynecol. 1998;179(6):1465-71.

Cite this article as: Sweed MS, Mostafa HA

Sammour HM, Ashour HA, Nadim MA, Ibrahim OI. Modified technique for sacrospinous-sacrotuberous ligament complex colpopexy in apical prolapse: preliminary results of a pilot randomized study. Int J Reprod Contracept Obstet Gynecol 2020;9:4785-91. 